\title{
Enhanced Wear Resistance of Ni/h-BN Composites with Graphene Addition Produced by Spark Plasma Sintering
}

\author{
Jiao $\mathrm{Xu}^{1,2} \cdot$ Dan-Qing $\mathrm{Yi}^{1,2} \cdot$ Qiang Cui ${ }^{1,2} \cdot$ Bin Wang ${ }^{1,2}$ \\ Received: 3 August 2018/Revised: 18 September 2018/Published online: 13 November 2018 \\ (C) The Chinese Society for Metals and Springer-Verlag GmbH Germany, part of Springer Nature 2018
}

\begin{abstract}
Ni-based self-lubricating composites containing a fixed amount of hexagonal boron nitride (h-BN) $(5 \mathrm{wt} \%)$ and different amounts of graphene $(0-1.5 \mathrm{wt} \%)$ were prepared by ultrasonic dispersion, high-energy ball milling, and spark plasma sintering. The effects of the graphene content on the physical, mechanical, and wear properties of the Ni/h-BN composites were evaluated. These properties were first enhanced with increasing graphene content, reaching optimal behavior for a graphene content of $1 \mathrm{wt} \%$, and then degraded with further graphene addition. Compared to the pure $\mathrm{Ni} / \mathrm{h}-\mathrm{BN}$ composite, the relative density, hardness, and bending strength of the composite with $1 \mathrm{wt} \%$ graphene increased by $2.7 \%, 7.4 \%$, and $6.3 \%$, respectively, while the friction coefficient decreased by $56 \%$ to 0.31 , and a reduction in wear rate by a factor of 5-15 was observed. The mechanism for improving the wear properties of the composite with added graphene was due to the formation of a graphene lubricating film on the worn surface, which increased the load bearing capacity of the surface and enhanced lubrication during wear.
\end{abstract}

Keywords Graphene $\cdot$ h-BN $\cdot$ Wear $\cdot$ Ni matrix composites

\section{Introduction}

Ball pressurizing mechanisms in tracked vehicle are often used to harsh conditions, such as high temperature, high rotational speed, humidity, and presence of dust. Poor contact between the ball and the matching cylinder in the ball pressurizing mechanism can impede the movement of the ball, resulting in brake failure. Currently, the polymer composites, asbestos, and $\mathrm{Cu}-$ or $\mathrm{Fe}$-based composites are used as sealing materials in such a mechanism due to their low friction coefficient. However, due to the poor hightemperature corrosion resistance of these materials, their useful lifetime is limited. Therefore, it is important to study new classes of materials with excellent mechanical

Available online at http://link.springer.com/journal/40195

Bin Wang

wangbin325@263.net

1 School of Material Science and Engineering, Central South University, Changsha 410083, China

2 Light Alloy Research Institute, Central South University, Changsha 410083, China properties, high-temperature friction, and wear resistance and corrosion resistance for use in the matching cylinder.

Metal matrix self-lubricating composites have attracted attention for such applications due to their excellent mechanical properties, low friction coefficients, and high wear resistance. Among them, Ni matrix self-lubricating composites with hexagonal boron nitride (h-BN) as the solid lubricant are widely used due to their good lubrication properties at high temperature [1-4]. In order to further improve the excellent mechanical and lubrication properties of such composites, various secondary phase particles are included [5-9]. Bolelli et al. [6] investigated the wear properties of $\mathrm{NiCrAlY} / \mathrm{Al}_{2} \mathrm{O}_{3} / \mathrm{h}-\mathrm{BN}$ composites and found that the addition of $\mathrm{Al}_{2} \mathrm{O}_{3}$ can increase the hardness of the material. They showed that $\mathrm{Al}_{2} \mathrm{O}_{3}$ and h-BN can promote the formation of a tribofilm and reduce the wear rate. Rajnesh et al. [8] showed that h-BN and Ag significantly improved the friction and wear behavior of Ni-based P/M composites, which was attributed to the presence of a compact transfer layer of wear debris. In addition, the materials have been developed with improved performance by adding h-BN and other solid lubricants into metal substrates, such as SS316L/h-BN/MoS 2 [10] and Cu/h-BN/ $\mathrm{C}$ [11]. However, the need for large volumes of secondary 
phase particles and h-BN is an important drawback limiting potential applications of these materials as lubricant additives.

Recently, graphene, with a two-dimensional structure of $s p^{2}$ carbon atoms arranged in a honeycomb lattice, has attracted tremendous attention for various applications owing to its high elastic modulus, large specific surface area, and high tensile strength [12]. The loosely stacked graphene sheets are bound by weak van der Waals forces and can be easily sheared along the basal plane of the crystalline lamellar structure under sliding stresses, providing an excellent lubrication mechanism [13]. Therefore, the study of graphene as a secondary phase particle for improving the mechanical and tribological properties of metal matrix composites has also been reported [14-18]. Algul et al. [14] reported that Ni/graphene composites have excellent load bearing capacity and lubrication ability at room temperature, which could effectively reduce the plastic deformation and friction coefficient during friction and wear. Muhammet et al. [15] reported that the friction coefficient of $\mathrm{Mg}$ was significantly reduced by the addition of graphene, and $\mathrm{Mg}-0.5 \mathrm{wt} \%$ graphene composites exhibited a minimum friction coefficient of 0.48 at $10 \mathrm{~N}$, which was lower than that of pure $\mathrm{Mg}(0.84)$.

Graphene-doped metal matrix composites have been prepared using various methods, such as chemical vapor deposition [19], electrodeposition [14, 20], laser sintering [21], and powder metallurgy [22, 23]. Spark plasma sintering (SPS) is a new rapid sintering technology for preparing high-density composites [24-26]. SPS has the advantages of rapid heating and a short sintering time [27], which can effectively inhibit grain growth and produce a compact structure after sintering. This technique is widely used in the preparation of metal matrix and ceramic matrix composites. Nieto et al. [28] prepared bulk graphene nanosheets by SPS under the conditions of $1850{ }^{\circ} \mathrm{C}$ and $80 \mathrm{MPa}$, which retained the graphene structure.

We propose that SPS can be used to prepare Ni/h$\mathrm{BN} /$ graphene composites in order to study the effect of graphene on the wear properties of $\mathrm{Ni} / \mathrm{h}-\mathrm{BN}$ composites. In this study, Ni matrix self-lubricating composites containing a fixed amount of h-BN and various graphene contents were prepared in order to investigate the effect of graphene on the mechanical and tribological properties of the composites. The tribological behavior and wear mechanism of the composites were evaluated for developing new-generation sealing materials for possible future ball pressurizing mechanism.

\section{Experimental}

\subsection{Materials}

Pure Ni (99.8\%) powder with a particle size of $10 \mu \mathrm{m}$ and h-BN powder with a particle size of $2 \mu \mathrm{m}$ were purchased from Changsha Tianjiu Company, China. Graphene nanosheet powder with a diameter of 5-10 $\mu \mathrm{m}$ and thickness of 3-10 nm was obtained from Nanjing Xianfeng Nano Material Company, China. Henceforth, the samples are referred to as $0 \mathrm{Gr}, 0.5 \mathrm{Gr}, 1 \mathrm{Gr}$, and $1.5 \mathrm{Gr}$, where the value corresponds to the graphene content (in wt\%), and the h-BN content was fixed to $5 \mathrm{wt} \%$.

First, graphene was dispersed in ethanol via ultrasonication for $1 \mathrm{~h}$. Then, h-BN powder was added to the graphene suspension and the mixture was ultrasonicated for $1 \mathrm{~h}$. Next, nickel powder was added to the suspension and mechanical stirring was applied for $30 \mathrm{~min}$ to produce a homogenous mixture. The suspension was placed in a ballmill container (ball-to-powder ratio of 6:1) and ball-milled for $9 \mathrm{~h}$ in an Ar atmosphere with a speed of $200 \mathrm{rpm}$. Then, the suspension was completely dried in a vacuum oven at $80{ }^{\circ} \mathrm{C}$. Finally, the mixed powders were placed in a graphite mold with an inner diameter of $60 \mathrm{~mm}$ and sintercured in a SPS apparatus. The sample was heated from room temperature to $1100{ }^{\circ} \mathrm{C}$ at a rate of $150{ }^{\circ} \mathrm{C} / \mathrm{min}$. The sample was kept at a pressure of $40 \mathrm{MPa}$ during sintering for $6 \mathrm{~min}$ and then cooled in the furnace. Samples of $10 \mathrm{~mm}$ diameter and $60 \mathrm{~mm}$ height were prepared. The composite without graphene (0Gr) was prepared following the same process as a control.

\subsection{Characterization}

The geometric density of the sample was determined using the Archimedes principle. The Vickers hardness of the samples was measured with a Brookfield hardness tester with a loading force of $1 \mathrm{~kg}$ and a dwell time of $15 \mathrm{~s}$. A universal testing machine (CSS-44100) was used to determine the three-point bending strength of the samples with a crosshead speed of $1 \mathrm{~mm} / \mathrm{min}$ and a gauge length of $25 \mathrm{~mm}$.

The friction and wear properties of the samples were tested using a ball-on-disk tribometer. GCr15 ball (above 58HRC hardness) with a diameter of $6 \mathrm{~mm}$ was employed as the counterpart. A rotation radius of $5 \mathrm{~mm}$ and sliding time of $30 \mathrm{~min}$ were used. The dry sliding wear tests were carried out under loads of $1,3,5$, and $9 \mathrm{~N}$ and a sliding speed of $200 \mathrm{rpm}$ at room temperature. Samples with dimension of $20 \mathrm{~mm} \times 15 \mathrm{~mm} \times 3 \mathrm{~mm}$ were prepared by sanding with 1200-grit sandpaper and ultrasonically washed with acetone prior to testing. The friction tests 
were repeated three times at each load. Friction coefficient versus time curves were automatically recorded by the system. The depth and width of the wear trace were measured using a dual-mode three-dimensional (3D) surface profiler (WTM-2E). The specific wear rate was calculated using $W=V F / S\left(\mathrm{~mm}^{3} / \mathrm{N} \mathrm{m}\right)$, where $V$ is the wear volume, $S$ is the total sliding distance, and $F$ is the applied load.

The microstructure and chemical composition of the samples were characterized using environmental scanning electron microscopy (ESEM; Quanta-200) equipped with an energy-dispersive X-ray spectrometry (EDS) system. Field emission scanning electron microscopy (FE-SEM; Sirion 200) was used to characterize the morphology of the powders before and after ball milling. X-ray diffractometry (XRD) using $\mathrm{Cu} K \alpha$ radiation $(\lambda=0.15418)$ with a scanning speed of $4 \% \mathrm{~min}$ was used to verify the phase and composition of the sample and the crystal structure of graphene. A laser microscopy confocal Raman spectrometer (inVia) with 514-nm laser excitation was used to analyze the graphene quality and the presence of graphene in the composites. Electron probe microanalysis (EPMA; JXA-8230) was used to demonstrate the distribution and contents of h-BN and graphene on the sample and wear surfaces.

\section{Results and discussion}

\subsection{Powder properties}

The microstructure of graphene is shown in Fig. 1a. It is clear that the graphene had a wrinkled and curled structure. In the XRD pattern shown in Fig. 1b, a clear broad peak at $2 \theta=26.21^{\circ}$ is seen, which corresponded to a plane spacing

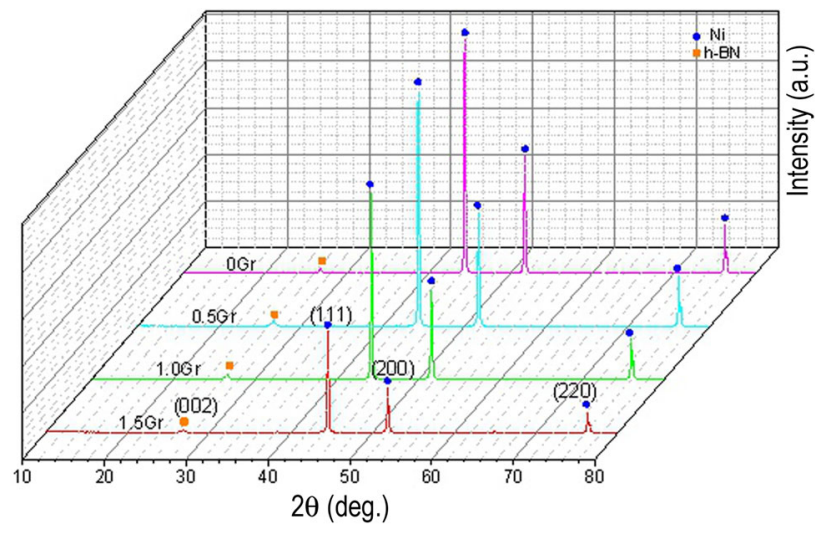

Fig. 2 3D X-ray diffraction patterns of the composites
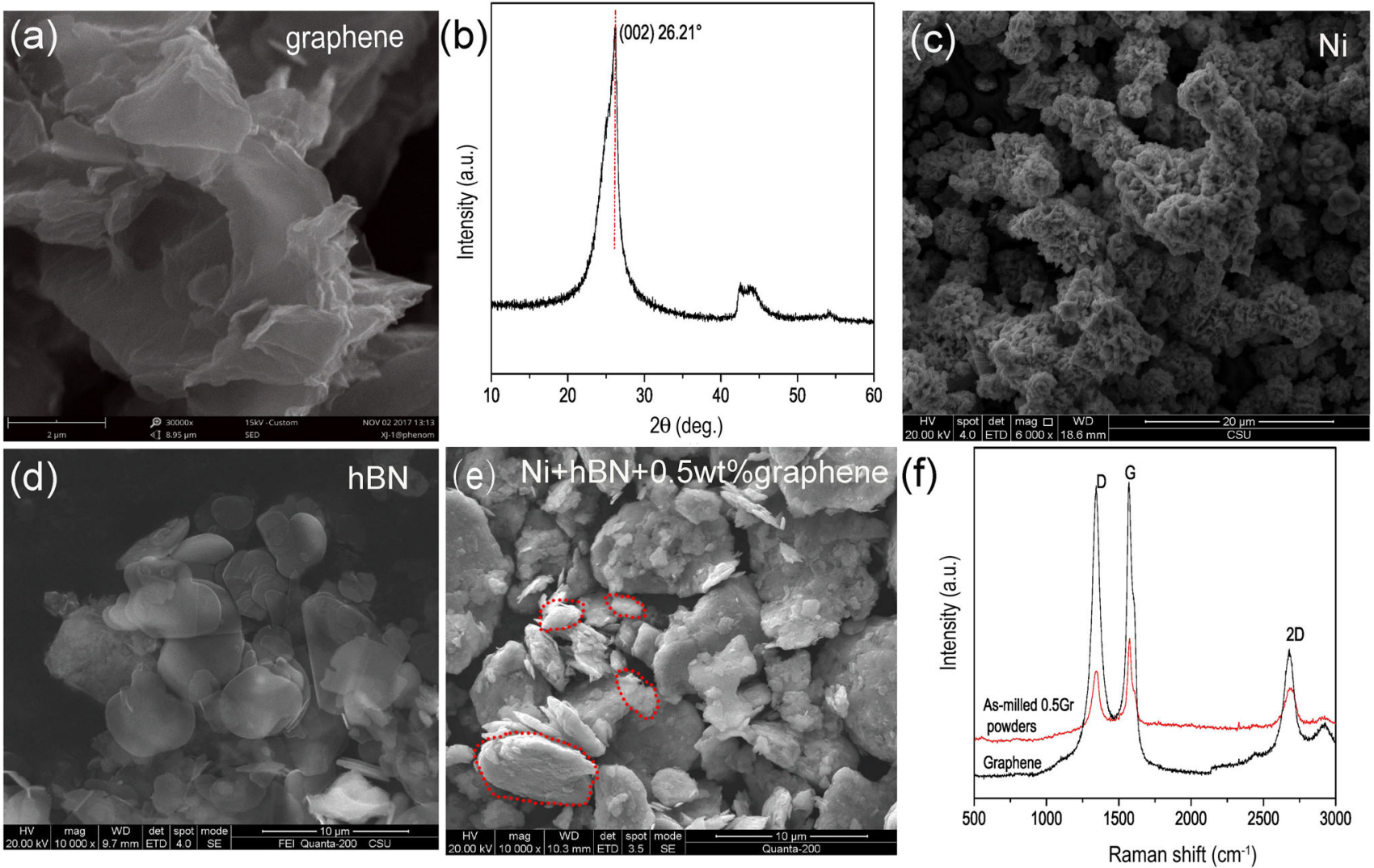

Fig. 1 Characterization of graphene, $\mathrm{Ni}, \mathrm{h}-\mathrm{BN}$, and as-milled $0.5 \mathrm{Gr}$ powders. a graphene; $\mathbf{b} \mathrm{XRD}$ pattern of graphene; SEM images of $\mathbf{c} \mathrm{Ni}$ powders, $\mathbf{d}$ h-BN powders, e as-milled $0.5 \mathrm{Gr}$ powders; $\mathbf{f}$ Raman spectra of graphene and as-milled $0.5 \mathrm{Gr}$ powders 
of graphene of $3.40 \AA$, according to the Bragg equation [29]. The typical morphologies of spherical nickel powder and lamellar h-BN are shown in Fig. 1c, d, respectively. The as-milled $0.5 \mathrm{Gr}$ powders were sheared into flat particles, and a small amount of the particles were broken after ball milling (Fig. 1e). The Raman spectra of graphene and as-milled $0.5 \mathrm{Gr}$ powders are shown in Fig. 1f. It is well known that the D peak is related to structural defects in graphene and the $G$ peak is a result of in-plane vibrations of

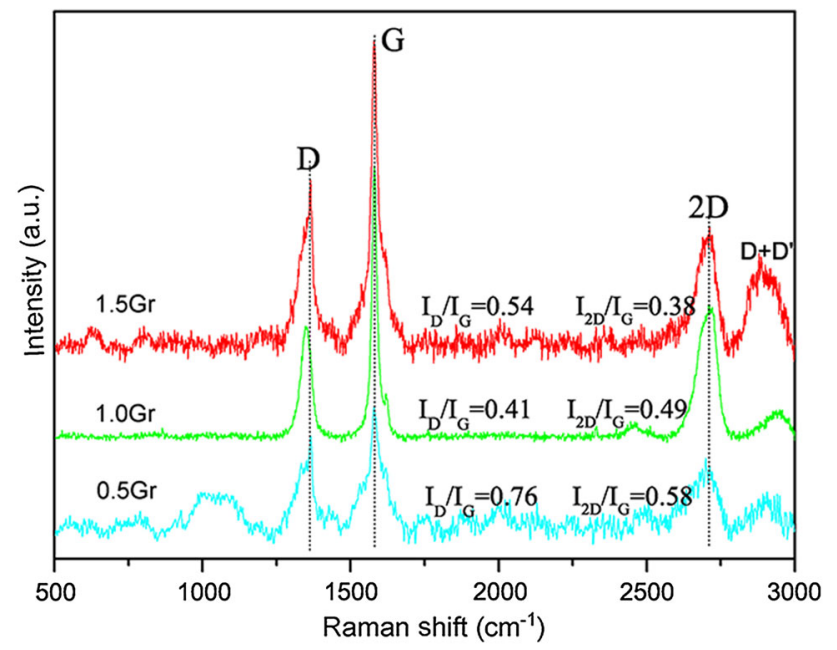

Fig. 3 Raman spectra of the composites carbon atoms. The $\mathrm{G}$ and $2 \mathrm{D}$ peaks can be used to determine the number of graphene layers and the quality of graphene. The ratio of the intensity of the $\mathrm{D}$ peak to that of the $\mathrm{G}$ peak, $I_{\mathrm{D}} / I_{\mathrm{G}}$, indicates the quality of graphene, where a smaller ratio relates to fewer defects. The $I_{\mathrm{D}} / I_{\mathrm{G}}$ of the asreceived graphene was 0.96 . The ratio of the intensity of the $2 \mathrm{D}$ peak to that of the $\mathrm{G}$ peak, $I_{2 \mathrm{D}} / I_{\mathrm{G}}$, reflects the number of graphene layers, where a smaller ratio relates to a higher number of graphene layers $[30,31]$. The $I_{2 \mathrm{D}} / I_{\mathrm{G}}$ of the as-milled $0.5 \mathrm{Gr}$ powder was 0.69 , which was smaller than that of as-received graphene (0.49), indicating that the number of graphene layers after ball milling decreased and the powder did not agglomerate.

\subsection{Composite Properties}

Figure 2 shows 3D XRD patterns of samples $0 \mathrm{Gr}, 0.5 \mathrm{Gr}$, $1.0 \mathrm{Gr}$, and $1.5 \mathrm{Gr}$. The XRD patterns of the composites showed three strong Ni peaks, while that corresponding to $\mathrm{h}$-BN was relatively weak as the atomic numbers of $\mathrm{B}$ and $\mathrm{N}$ were smaller than that of $\mathrm{Ni}$. However, compared to the control, the composite samples showed peak broadening with the diffraction peaks shifting to lower angles. With increasing graphene content, the intensity of the Ni (111) peak decreased gradually, which was attributed to an increase in the polycrystallinity of the nickel matrix composites. This was similar to the observation reported by
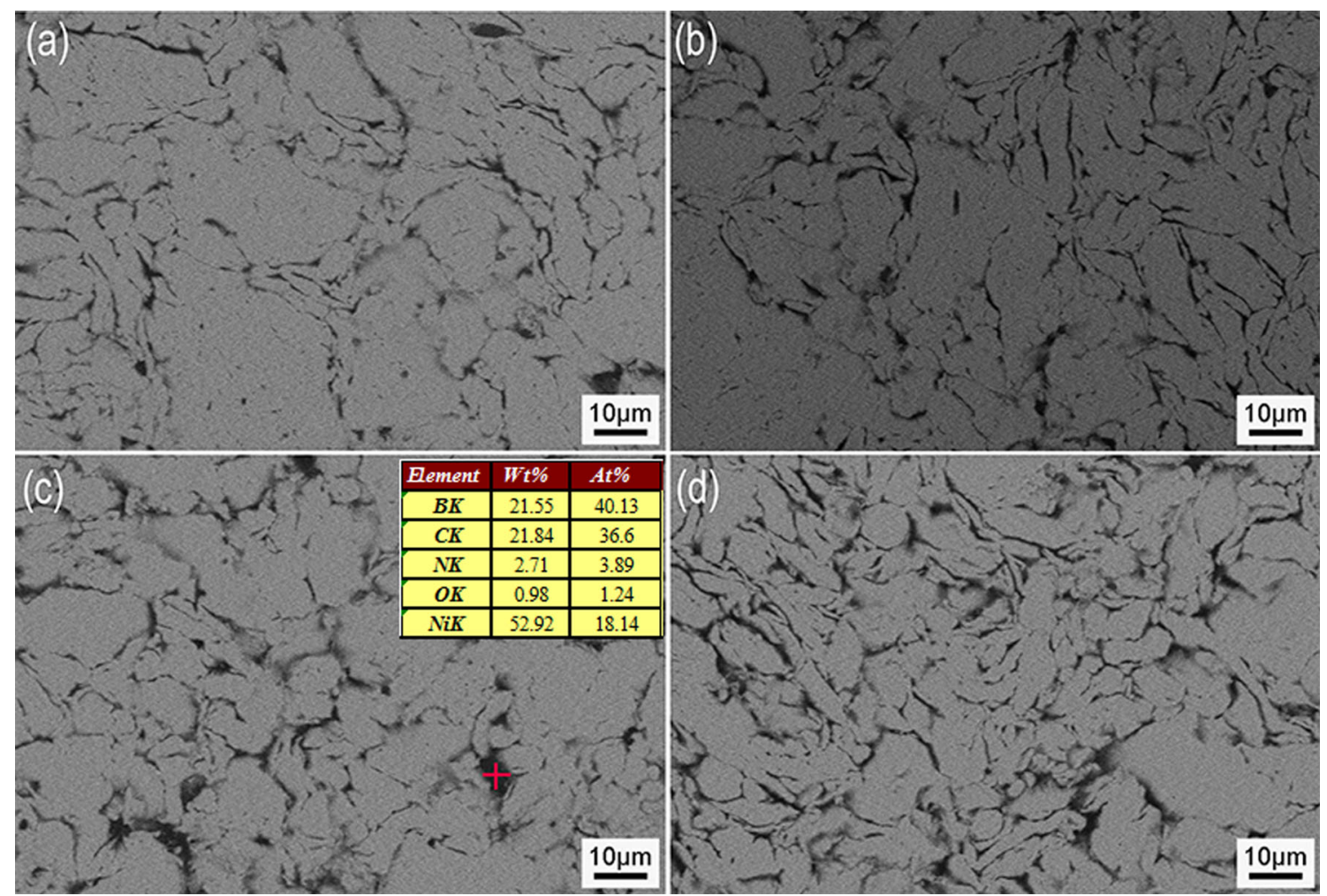

Fig. 4 Microstructures of the composites. a $0 \mathrm{Gr}$; b $0.5 \mathrm{Gr}$; c $1.0 \mathrm{Gr}$; d $1.5 \mathrm{Gr}$ 

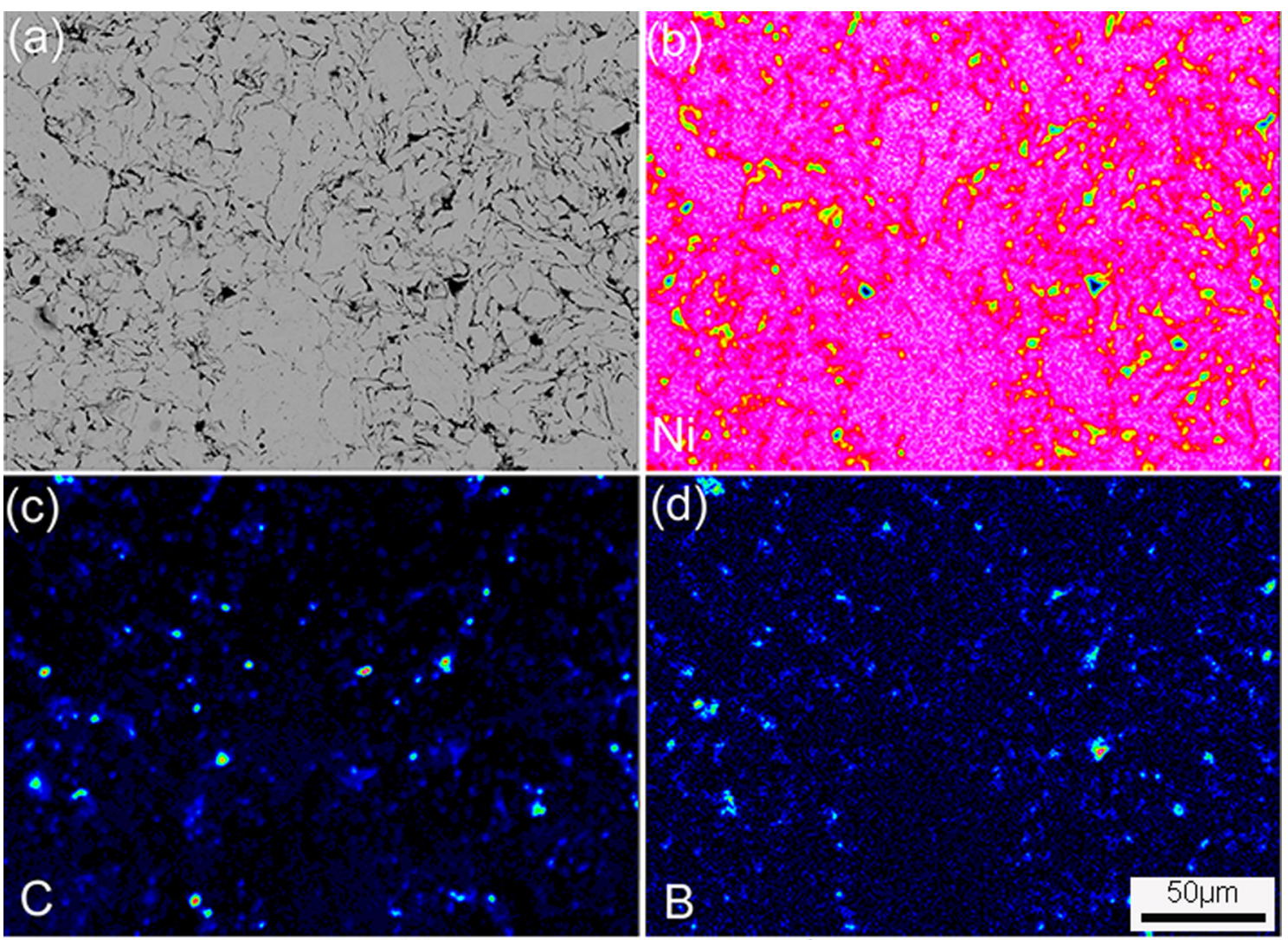

High

Low

Fig. 5 a Microstructure of sample $0.5 \mathrm{Gr}$; $\mathbf{b}$ nickel, $\mathbf{c}$ carbon, and $\mathbf{d}$ boron EPMA mapping images of a

Table 1 Physical and mechanical properties of the composites

\begin{tabular}{lllll}
\hline Samples & Geometric density $\left(\mathrm{g} / \mathrm{cm}^{3}\right)$ & Relative density $(\%)$ & Hardness $(\mathrm{HV})$ & Bending strength (MPa) \\
\hline $0 \mathrm{Gr}$ & 7.372 & 94.0 & $110 \pm 2.0$ & $281 \pm 0.7$ \\
$0.5 \mathrm{Gr}$ & 7.330 & 95.4 & $112 \pm 2.3$ & $283 \pm 1.2$ \\
$1.0 \mathrm{Gr}$ & 7.202 & 96.5 & $118 \pm 3.6$ & $298 \pm 1.6$ \\
$1.5 \mathrm{Gr}$ & 7.198 & 95.1 & $105 \pm 3.3$ & $297 \pm 2.1$ \\
\hline
\end{tabular}

Ren et al. [32]. In addition, no XRD peaks related to graphene were observed for the $\mathrm{Ni} / \mathrm{h}-\mathrm{BN} /$ graphene composites.

To verify the presence of graphene, the Raman spectra of the three composite samples are shown in Fig. 3. Three clear Raman peaks were observed at 1364, 1578, and $2710 \mathrm{~cm}^{-1}$ corresponding to the D, G, and 2D peaks of graphene, respectively. This confirmed that graphene was present in the composites and its structure was maintained. The $I_{\mathrm{D}} / I_{\mathrm{G}}$ ratios of the composites indicated that the SPS process did not increase the graphene defect density. The observed decrease in the $I_{2 \mathrm{D}} / I_{\mathrm{G}}$ ratio from 0.58 to 0.38 in the composites indicated that graphene agglomerated to some degree.

Back-scattered electron (BSE) maps of the composites are shown in Fig. 4. The gray areas corresponded to the majority of the Ni substrate, while the black areas represent the accumulation points of pores and solid lubricants in the substrate [33]. As the graphene content increased, the volume of the black areas gradually increased, which inhibited growth of $\mathrm{Ni}$ particles, where excessive amounts agglomerated in the form of pockets containing pores (Fig. 4d). From the results of the EDS analysis shown in the inset in Fig. 4c, these black areas were clusters of solid lubricant particles containing h-BN and graphene.

The microstructure and elemental distribution of sample $0.5 \mathrm{Gr}$ are shown in Fig. 5, where it can be seen that h-BN and graphene were generally uniformly dispersed and coexisted in the pores. This is probably due to the similar sheet structure of both materials, neither of which participated in the sintering reaction [34], resulting in these materials being forced into the sintering neck and forming 

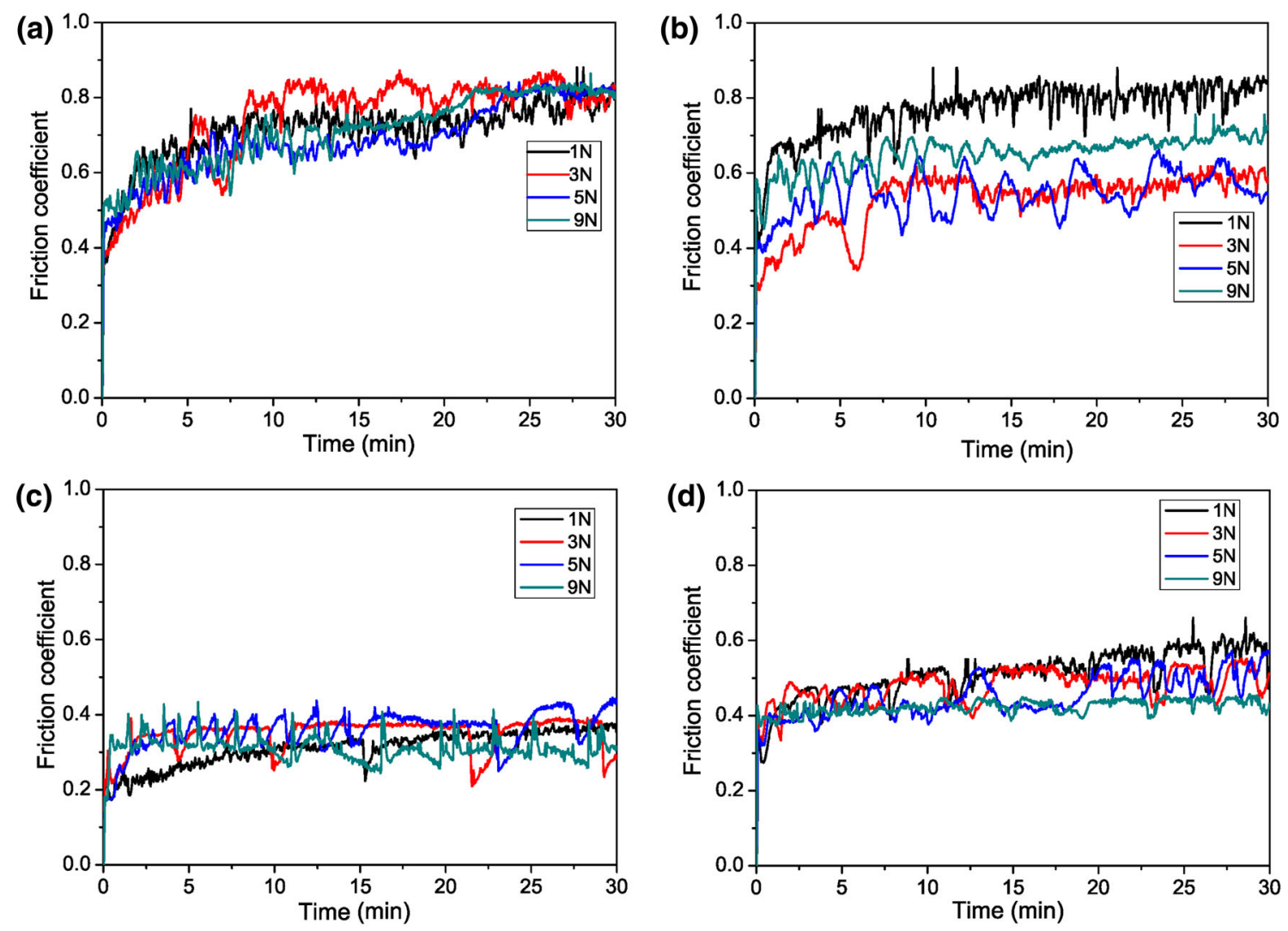

Fig. 6 Friction coefficients of the composites a $0 \mathrm{Gr}$; b $0.5 \mathrm{Gr}$; c $1.0 \mathrm{Gr}$; d $1.5 \mathrm{Gr}$ under different loads
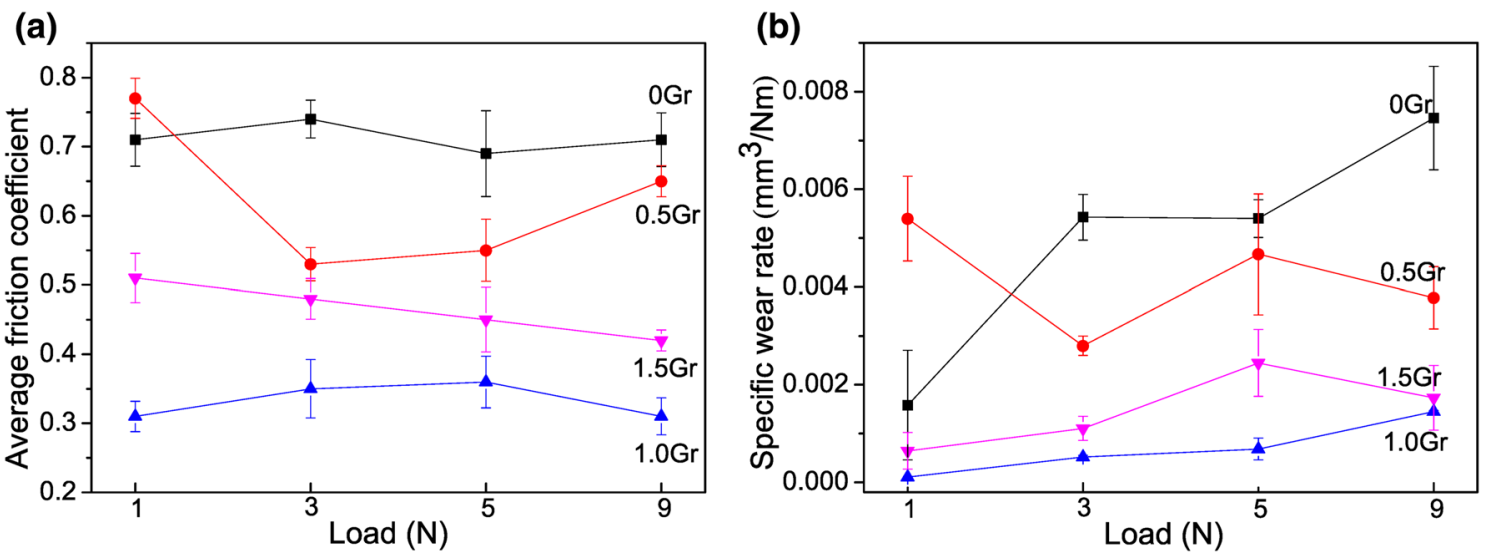

Fig. 7 a Average friction coefficients, b specific wear rates of the composites under different loads

pores [35]. Further, the concentrations of boron and carbon were relatively high in the regions with large pores, which is beneficial for the lubricating effect of the composites [36, 37].

Table 1 shows the physical and mechanical properties of the composites. With increasing graphene content, the geometric density of the composites decreased gradually. The relative density increased by $2.7 \%$ (from 94.0 to $96.5 \%$ ), the hardness increased by $7.4 \%$ (from 110.2 to 118.4 HV), and bending strength increased by $6.3 \%$ (from
280.5 to $298.1 \mathrm{MPa}$ ) with the addition of $1.0 \mathrm{wt} \%$ graphene compared to the control. The improvement in the mechanical properties was attributed to the strengthening effect of the graphene. Residual stress was generated due to the difference in thermal expansion coefficients of the matrix and graphene during sintering $\left(\mathrm{Ni}=13.4 \times 10^{-6} /\right.$ $\left.\mathrm{K}, \mathrm{Gr}=0.9 \times 10^{-6} / \mathrm{K}\right)$, which led to an increase in dislocation density and corresponding strengthening of the composites [38]. During bending deformation, graphene effectively withstood the load and significantly enhanced 


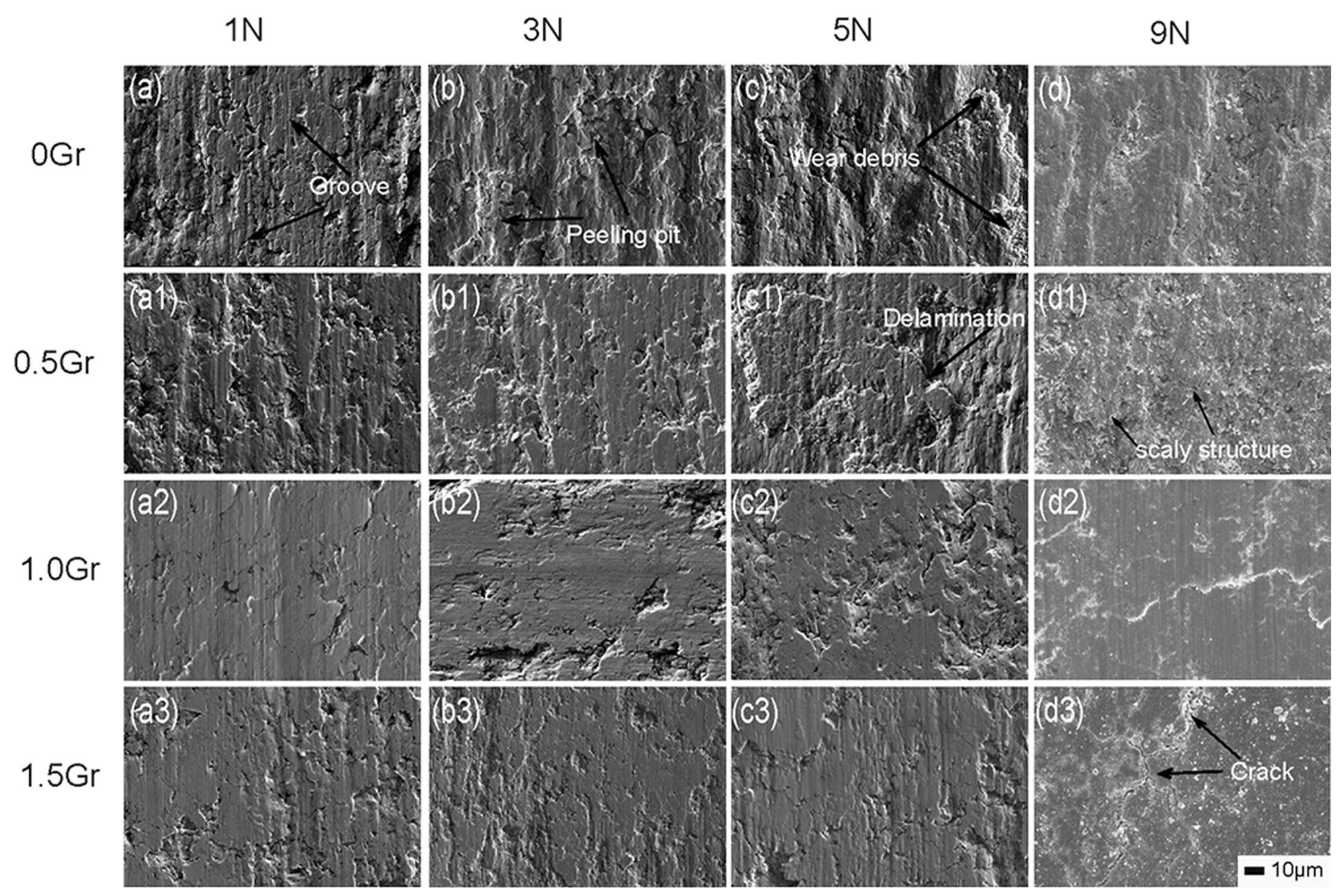

Fig. 8 SEM images of the worn surfaces of the composites under different loads

Width $=2 \mu \mathrm{m}$
Depth $=140 \mu \mathrm{m}$

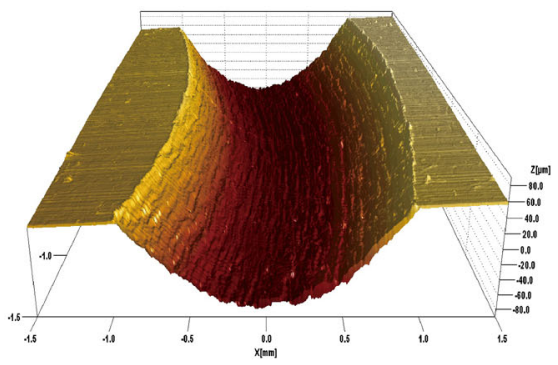

(c)

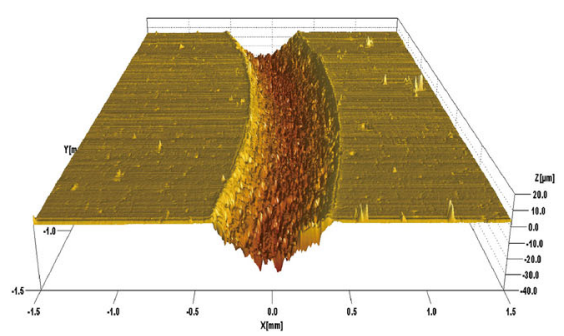

(b)

Width $=1.5 \mu \mathrm{m}$

Depth $=100 \mu \mathrm{m}$

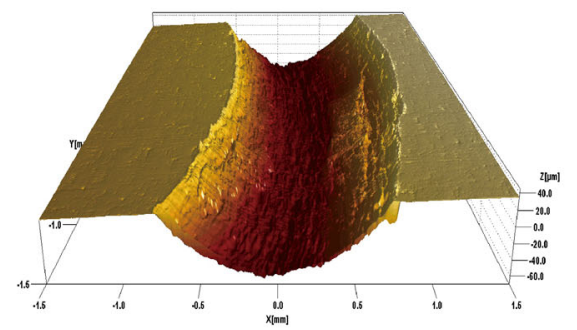

(d)

Width $=1.5 \mu \mathrm{m}$

Depth $=68 \mu \mathrm{m}$

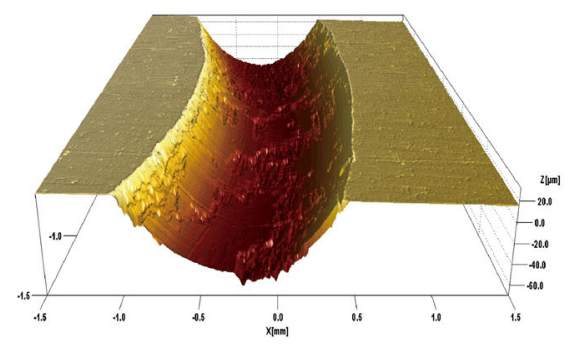

Fig. $93 \mathrm{D}$ topography of the composites at $5 \mathrm{~N}$. a $0 \mathrm{Gr}$; b $0.5 \mathrm{Gr}$; c $1.0 \mathrm{Gr}$; d $1.5 \mathrm{Gr}$ 
the strength of the matrix. However, for a graphene content of $1.5 \mathrm{wt} \%$, the mechanical properties of the composites became worse than those of the control, due to the partial aggregation of solid lubricant, resulting in weakened interfacial bonding, which reduces the ability of graphene to transfer stress [22]. Our results are consistent with those of Song et al. [18] who observed that the mechanical properties of Ti-MLG composites fabricated using SPS degraded when the graphene content reached $1.5 \mathrm{wt} \%$.

\subsection{Wear Performance}

Typical friction coefficient versus sliding time curves for the composites are shown in Fig. 6. It can be seen that the friction coefficient of all composites increased quickly with increasing sliding time and remained stable after a certain period. With the addition of graphene, the friction coefficient of all composites decreased compared to the control, showing a minimum for a graphene content of $1 \mathrm{wt} \%$. This indicates that the combined addition of small amounts of graphene and h-BN can result in an enhanced lubrication effect.

The average friction coefficient and specific wear rate of the composites under different loads at $200 \mathrm{rpm}$ are shown in Fig. 7. The friction coefficient and wear rate of all samples showed similar curves under different loads, except for $0.5 \mathrm{Gr}$ at $1 \mathrm{~N}$. As the graphene content increased, the friction coefficient and wear rate of the samples first decreased and then increased. Sample 1.0Gr showed excellent tribological properties. Figure 7a clearly shows that the friction coefficient of $0 \mathrm{Gr}$ was close to the measured value and remained stable at $\sim 0.7$ under different loads, which is consistent with previous results [39]. In addition, sample $1.0 \mathrm{Gr}$ showed the lowest friction coefficient (0.31-0.36), while that of $1.5 \mathrm{Gr}$ increased slightly within the range of $0.42-0.51$ under $1-9 \mathrm{~N}$. However, for samples with higher graphene contents (1.0 and $1.5 \mathrm{wt} \%$ ), the friction coefficient decreased with increasing load. This is different from the observation that solid lubricants improve the lubrication performance of the metal matrix under high load [5, 40].

Figure $7 \mathrm{~b}$ shows that the wear rate of the composites increased with increasing load. The wear rate of sample $0 \mathrm{Gr}$ increased rapidly, reached the maximum value of $7.46 \times 10^{-3} \mathrm{~mm}^{3} \mathrm{~N}^{-1} \mathrm{~m}^{-1}$ at $9 \mathrm{~N}$. The wear rate of sample $0.5 \mathrm{Gr}$ exhibited some fluctuations. The wear rates of samples $1.0 \mathrm{Gr}$ and $1.5 \mathrm{Gr}$ increased slowly, while that of $1.0 \mathrm{Gr}$ remained at the lowest level of $(0.107-1.45) \times 10^{-3} \mathrm{~mm}^{3} \mathrm{~N}^{-1} \mathrm{~m}^{-1} \quad$ under $\quad 1-9 \mathrm{~N}$, respectively, which was a reduction of a factor of 5-15 compared to the control. It is worth noting that the wear rates of the composites with graphene were more stable under the measured load range, and only the wear
Fig. 10 EPMA maps of the worn surfaces of graphene-reinforced $\mathrm{Ni} /$ h-BN composites with different contents of graphene at $9 \mathrm{~N}$

rate of the control increased rapidly, which was attributed to the excellent lubricating property of graphene [41]. The wear rate of the samples studied here was slightly higher than that of Ni-based alloys in the literature. In order to reduce the wear of the matching surface of the ball pressurizing mechanism, the hardness of the sealing material should not be too high, so pure Ni is used as a substrate. This may lead to a slightly higher wear rate.

\subsection{Wear Mechanism}

In order to further study the wear mechanism, the morphologies of the worn surfaces of the composites under different loads are shown in Fig. 8. The worn surface of sample 0Gr under $1 \mathrm{~N}$ clearly exhibits distinct fine furrows, which is generally attributed to plowing wear (Fig. 8a). With increasing load to $3 \mathrm{~N}$ and $5 \mathrm{~N}$ (Fig. 8b, c), respectively, peeling pits and residual wear debris were observed, indicating that the wear mechanism was dominated by plowing and delamination. Higher loads resulted in deeper delamination. The plastic flow of the material (under $9 \mathrm{~N}$ ) shown in Fig. 8d indicated that the wear mechanism changed to delamination and plastic deformation as the hardness of protrusions on the surface of the GCr15 ball was considerably larger than that of the $\mathrm{Ni} / \mathrm{h}-\mathrm{BN}$ composite.

The images shown in Fig. 8a1-d3 of the worn surfaces of the composite samples revealed that the addition of graphene resulted in relatively smooth worn surface with relatively shallow grooves. There are many parallel furrows on the worn surfaces of sample $0.5 \mathrm{Gr}$ in Fig. 8a1, b1, while delamination and the scale-like structure caused by plastic deformation are observed in Fig. 8c1, d1. Sample $1.0 \mathrm{Gr}$ showed a very smooth worn surface, with only a minor scratch and few adhesive features visible at $1 \mathrm{~N}$ (Fig. 8a2) due to the excellent load bearing capacity of graphene [14, 18]. Some small cavities and delamination were clearly observed at 3 and $5 \mathrm{~N}$ (Fig. 8b2, c2), respectively, as the extruded graphene was gradually worn away. When the load increased to $9 \mathrm{~N}$, graphene was moved to the surface under the action of extrusion stress and distributed over the surface via shear stress to enhance the lubrication effect (Fig. 8d2), which reduced the friction coefficient. However, under the influence of friction heat, the worn surface became weaker and easier to damage, resulting in an increase in the wear rate [42]. The main wear mechanism under the different loads was abrasion. Parallel grooves appeared again on the worn surface of 


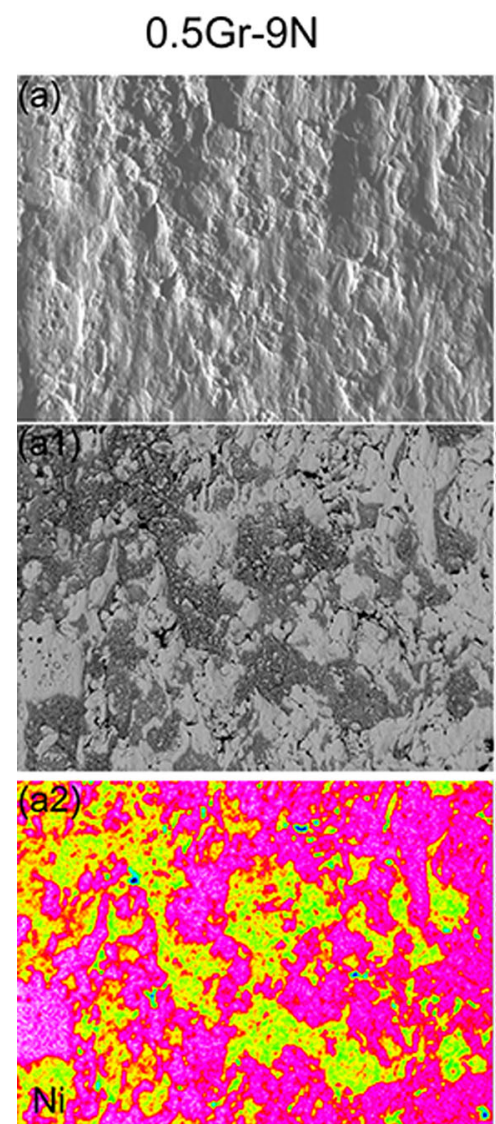

1.0Gr-9N

$1.5 \mathrm{Gr}-9 \mathrm{~N}$
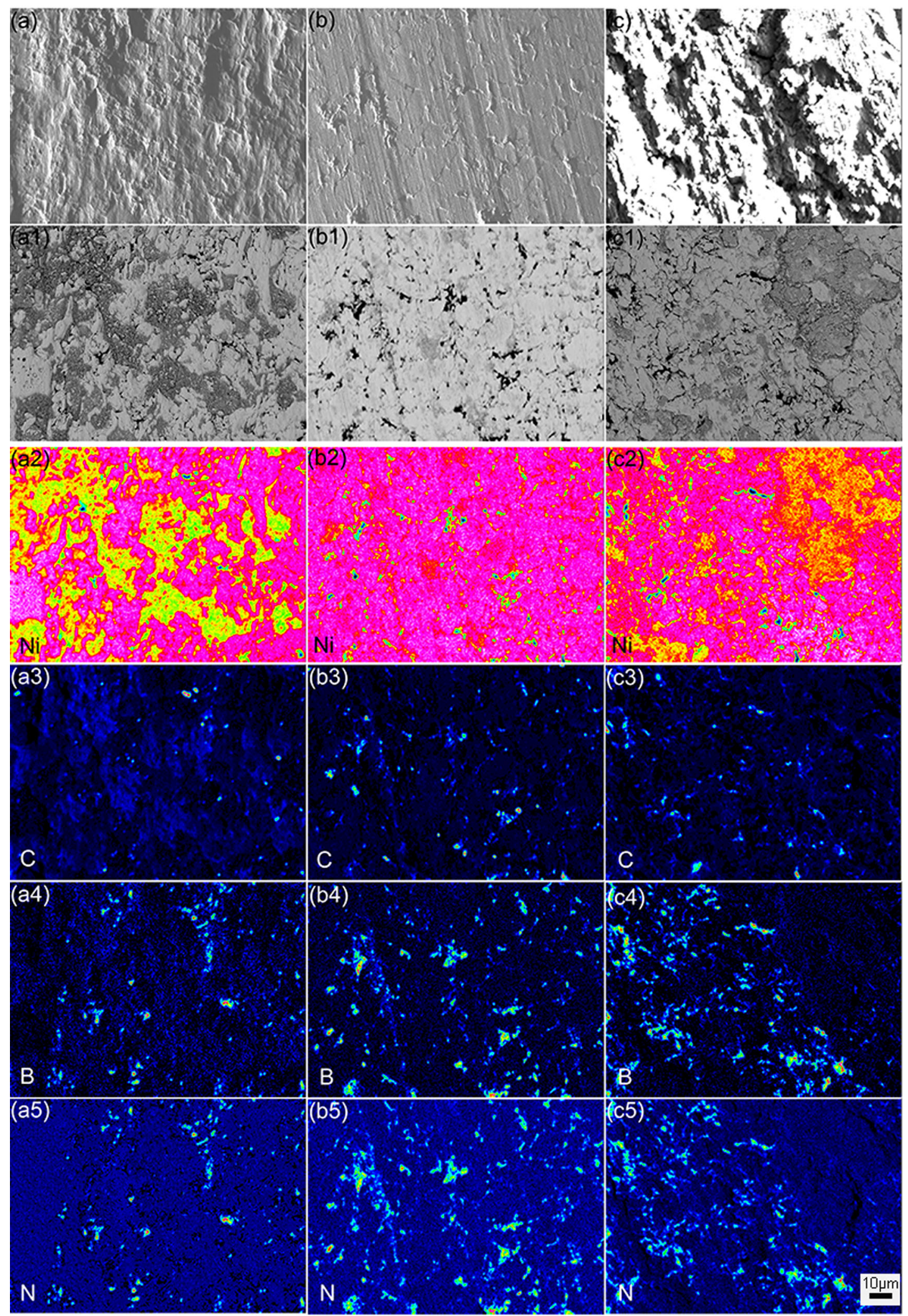

High 
sample 1.5Gr (Fig. 8a3-c3), while cracks perpendicular to the sliding direction and some fine wear debris accumulated on the wear track were observed at higher load (Fig. 8d3). The formation of cracks was attributed to surface deformation hardening under high load [10], indicating dominant wear mechanisms of abrasive wear and delamination.

3D topographies of the worn surfaces of the composites at a load of $5 \mathrm{~N}$ are shown in Fig. 9. It can be clearly seen that sample 1.0Gr showed the best wear resistance of all samples under the same load. The worn surface of sample 0Gr had obvious parallel rough grooves, and the grooves on sample $0.5 \mathrm{Gr}$ were slightly thinner and material accumulation occurred, while a highly worn surface was observed for sample $1.5 \mathrm{Gr}$. These observations were in good agreement with the results shown in Fig. 8c, c1-c3. With increasing graphene content, the width and depth of the wear scars of the composites reduced significantly. Minimum values of 0.8 and $20 \mu \mathrm{m}$, respectively, were obtained for a graphene content of $1 \mathrm{wt} \%$, corresponding to a reduction of $60 \%$ and $85.7 \%$, respectively, compared to sample 0Gr.

To further investigate the lubrication mechanism of graphene and h-BN during sliding friction, Fig. 10 shows EPMA maps of the worn surfaces of the Ni/h-BN/graphene composites. The secondary electron image of the worn surface is shown in the first row, and the BSE image is in the second row. Ni was identified over most of the worn surface, while $\mathrm{C}, \mathrm{B}$, and $\mathrm{N}$ were distributed along the direction of the scratch, which is related to the direction of the solid lubricant particles in the matrix [43]. The $\mathrm{C}$ content of the worn surface increased with increasing graphene content up to $1 \mathrm{wt} \%$ and then did not significantly increase. In addition, the distribution area and concentration of $\mathrm{B}$ and $\mathrm{N}$ on the worn surface of samples $1.0 \mathrm{Gr}$ and $1.5 \mathrm{Gr}$ were clearly higher than those of $0.5 \mathrm{Gr}$, which implied that it was easier to move h-BN to the surface with higher graphene contents.

The superior wear performance of sample $1.0 \mathrm{Gr}$ was attributed to both the denser microstructure and the better mechanical properties. As the graphene content increased, the fraction of graphene extruded to the worn surface increased, which decreased the contact area between the friction pairs and increased the lubrication effect and surface bearing capacity. However, the high content of solid lubricants in sample $1.5 \mathrm{Gr}$ hindered interfacial bonding due to local agglomeration. The weak interface resulted in the lubricating phase being easily removed during friction, leaving large pores that resulted in crack nucleation and propagation, further increasing wear. It is well known that hardness is proportional to the wear resistance of materials. This is because a higher hardness can limit plastic deformation and accordingly reduce the friction coefficient and wear rate. While sample $1.0 \mathrm{Gr}$ showed excellent mechanical properties, the worn surface of sample $1.5 \mathrm{Gr}$ showed deeper grooves at high load and deposition of solid lubricants, resulting in an uneven surface and enhanced wear.

Based on the above results, the proposed wear mechanism for $\mathrm{Ni} / \mathrm{h}-\mathrm{BN} /$ graphene composite is as follows. During the composite wearing, the $\mathrm{h}-\mathrm{BN}$ particles were removed from the matrix to the surface or into the pits without lubrication due to its low metastability and adhesion. Moreover, h-BN particles, as the soft phase, were distributed at the grain boundaries, which was the source of crack nucleation during the friction process. Graphene formed a lubricating film on the worn surface under the action of extrusion and shear stresses as this material does not easily form surface asperities, but rather spreads them. Hence, this film improved wear resistance due to its good lubrication and surface bearing capacity.

\section{Conclusions}

$\mathrm{Ni} / \mathrm{h}$-BN/graphene self-lubricating composites were prepared by SPS and the effects of different graphene contents on the tribological behavior and wear mechanism under different loads were studied. The main conclusions are as follows:

1. The physical, mechanical, and wear properties of the composites firstly improved and then degraded with increasing graphene content, where a content of $1 \mathrm{wt} \%$ was considered optimum.

2. In the case of the optimum Ni/h-BN/graphene (1 wt $\%$ ) sample, the relative density, hardness, and bending strength were $96.5 \%, 118.4 \mathrm{HV}$, and $298.1 \mathrm{MPa}$, which were significant improvements of $2.7 \%, 7.4 \%$, and $6.3 \%$ compared to the control sample. In addition, the friction coefficient decreased by $56 \%$ to 0.31 , while a 5-15-fold reduction in the wear rate was observed compared to the control.

3. The improved wear properties of the composite with graphene were attributed to the formation of the graphene lubricating film on the worn surface, which improves the load bearing capacity and lubricating effect during wear.

Acknowledgement The authors gratefully acknowledge Program of the Ministry of Education in China (2011).

\section{References}

[1] O.A.M. Elkady, A. Abu-Oqail, E.M.M. Ewais, M. EI-Sheikh, J. Alloys Compd. 625, 309 (2015) 
[2] S. Mahathanabodee, T. Palathai, S. Raadnui, R. Tongsri, N. Sombatsompop, Mater. Des. 46, 588 (2013)

[3] S. Zhang, J. Zhou, B. Guo, H. Zhou, Y. Pu, J. Chen, Mater. Sci. Eng., A 491, 47 (2009)

[4] M.V. Gorshenkov, S.D. Kaloshkin, V.V. Tcherdyntsev, V.D. Danilov, V.N. Gulbin, J. Alloys Compd. 536, 126 (2012)

[5] H. Chi, L. Jiang, G. Chen, P. Kang, X. Lin, G. Wu, Mater. Des. 87, 960 (2015)

[6] G. Bolelli, A. Candeli, L. Lusvarghi, A. Ravaux, A. Denoirjean, S. Valette, C. Chazelas, E. Meillot, L. Bianchi, Wear 378-379, 68 (2017)

[7] S. Farahany, H. Ghandvar, N.A. Nordin, A. Ravaux, K. Cazes, A. Denoirjean, S. Valette, C. Chazelas, E. Meillot, L. Bianchi, J. Mater. Sci. Technol. 32, 1083 (2016)

[8] R. Tyagi, D. Xiong, J. Li, Wear 270, 423 (2011)

[9] W. Zhai, X. Shi, K. Yang, Y. Huang, L. Zhou, W. Lu, Acta Metall. Sin. (Engl. Lett.) 30, 1 (2017)

[10] S. Mahathanabodee, T. Palathai, S. Raadnui, R. Tongsri, N. Sombatsompop, Wear 316, 37 (2014)

[11] B. Chen, Q. Bi, J. Yang, Y. Xia, J. Hao, Tribol. Int. 41, 1145 (2008)

[12] X. Sheng, W. Cai, L. Zhong, D. Xie, X. Zhang, Ind. Eng. Chem. Res. 54(2), 150107081819009 (2015)

[13] D. Berman, A. Erdemir, A.V. Sumant, Mater. Today 17, 31 (2014)

[14] H. Algul, M. Tokur, S. Ozcan, M. Uysal, T. Cetinkaya, H. Akbulut, A. Alp, Appl. Surf. Sci. 359, 340 (2015)

[15] M.E. Turan, Y. Sun, Y. Akgul, Y. Turen, H. Ahlatci, J. Alloys Compd. 724, 14 (2017)

[16] J. Li, X. Zhang, L. Geng, Mater. Des. 144, 159 (2018)

[17] M. Uysal, H. Akbulut, M. Tokur, H. Algul, T. Cetinkaya, J. Alloys Compd. 654, 185 (2016)

[18] Y. Song, Y. Chen, W.W. Liu, W.L. Li, Y.G. Wang, D. Zhao, X.B. Liu, Mater. Des. 109, 256 (2016)

[19] G. Odahara, S. Otani, C. Oshima, M. Suzuki, T. Yasue, T. Koshikawa, Surf. Sci. 605, 1095 (2011)

[20] D. Kuang, L. Xu, L. Liu, W. Hua, Y. Wu, Appl. Surf. Sci. 273, $484(2013)$

[21] Z. Hu, G. Tong, D. Lin, C. Chen, H. Guo, J. Xu, L. Zhou, J. Mater. Process. Technol. 231, 143 (2016)

[22] H. Yue, L. Yao, X. Gao, S. Zhang, E. Guo, H. Zhang, X. Lin, B. Wang, J. Alloys Compd. 691, 755 (2017)
[23] J. Wang, Z. Li, G. Fan, H. Pan, Z. Chen, D. Zhang, Scr. Mater. 66, 594 (2012)

[24] L.H. Liu, C. Yang, F. Wang, S.G. Qu, X.Q. Li, W.W. Zhang, Y.Y. Li, L.C. Zhang, Mater. Des. 79, 1 (2015)

[25] L.H. Liu, C. Yang, L.M. Kang, Y. Long, Z.Y. Xiao, P.J. Li, L.C. Zhang, Mater. Sci. Eng., A 650, 171 (2016)

[26] C. Yang, L.M. Kang, X.X. Li, W.W. Zhang, D.T. Zhang, Z.Q. Fu, Y.Y. Li, L.C. Zhang, E.J. Lavernia, Acta Mater. 132, 491 (2017)

[27] H.B. Feng, Y. Zhou, D.C. Jia, Mater. Sci. Technol. 11, 327 (2003)

[28] A. Nieto, D. Lahiri, A. Agarwal, Carbon 50, 4068 (2012)

[29] T.D. Shen, W.Q. Ge, K.Y. Wang, M.X. Quan, J.T. Wang, W.D. Wei, C.C. Koch, Nanostruct. Mater. 7, 393 (1996)

[30] C. Ferrari, J.C. Meyer, V. Scardaci, C. Casiraghi, M. Lazzeri, F. Mauri, S. Piscanec, D. Jiang, K.S. Novoselov, S. Roth, A.K. Geim, Phys. Rev. Lett. 97, 187401 (2006)

[31] M.S. Dresselhaus, A. Jorio, M. Hofmann, G. Dresselhaus, R. Saito, Nano Lett. 10, 751 (2010)

[32] Z. Ren, N. Meng, K. Shehzad, Y. Xu, S. Qu, B. Yu, J.K. Luo, Nanotechnology 26, 065706 (2015)

[33] H. Gisele, J.M. Kelen, C.G. Priscilada et al., Wear 376-377, 1084 (2017)

[34] P. Yu, L.C. Zhang, W.Y. Zhang, J. Das, K.B. Kim, J. Eckert, Mater. Sci. Eng., A 444, 206 (2007)

[35] T. Li, D. Yi, J. Hu, J. Xu, J. Liu, B. Wang, J. Alloys Compd. 723, 345 (2017)

[36] Y. Su, Y. Zhang, J. Song, L. Hu, Wear 372-373, 130 (2017)

[37] L. Rapoport, A. Moshkovich, V. Perfilyev, I. Lapsker, G. Halperin, Y. Itovich, I. Etsion, Surf. Coat. Technol. 202, 3332 (2008)

[38] H. Porwal, P. Tatarko, R. Saggar, S. Grasso, M.K. Mani, I. Dlouhý, J. Dusza, M.J. Reece, Ceram. Int. 10, 12067 (2014)

[39] D. Buckley, ASLE Trans. 21, 118 (1976)

[40] R. Harichandran, N. Selvakumar, Int. J. Mech. Sci. 000, 1 (2017)

[41] J.L. Zou, X.L. Shi, Q. Shen, K. Yang, Y.C. Huang, A. Zhang, Y.F. Wang, Q.X. Zhang, Acta Metall. Sin. (Engl. Lett.) 30, 193 (2017)

[42] C.D. Li, X.J. Wang, W.Q. Liu, K. Wu, H.L. Shi, C. Ding, X.S. $\mathrm{Hu}$, M.Y. Zheng, Mater. Sci. Eng., A 597, 264 (2014)

[43] W. Zhai, X. Shi, M. Wang, Z. Xu, J. Yao, S. Song, Y. Wang, Q. Zhang, J. Compos. Mater. 48, 3727 (2014) 